\title{
Активный вариант синдрома кандинского-клерамбо при шизофрении
}

\author{
Асадов Б.М. ${ }^{1}$ \\ ${ }^{1}$ Кафедра Психиатрии Азербайджсанского Медииинского Интитута. \\ e-mail: bilal_44@mail.ru \\ Тел. +994502105143
}

Ключевые слова: шизофрения, потребности, члены семьи, услуги

Актуальность исследования. В последние годы появился ряд исследований, посвященных изучению особенностей становления, формирования, психопатологического строения и специфической нозологической окраски синдрома Кандинского-Клерамбо $[1 ; 2 ; 6 ; 9$ и др.]. Однако, анализ психиатрической литературы показывает, что большинство исследований проведено в плане расширения нозологических форм психозов, в рамках которых встречается синдром КандинскогоКлерамбо, нежели в плане глубокого клиникопсихопатологического исследования этого сложного психопатологического состояния. В то же время, в структуре самого синдрома обнаруживаются психопатологические особенности, не ставшие еще предметом специального исследования.

Материал и методы исследования. Настоящая работа основана на обобщении результатов клинико-психопатологического и катамнестического исследования 203 больных различными типами течения шизофрении, у которых в клинической картине в качестве ведущего психопатологического расстройства выступали психопатологические феномены классического и активного вариантов синдрома Кандинского-Клерамбо.

Адекватными поставленным задачам оказались клиникопсихопатологический и катамнестический методы исследования, позволившие изучить особенности структуры, механизмы формирования, диагностическое

и прогностическое значение психопатологических феноменов активного варианта синдрома Кандинского-Клерамбо.

Результаты исследования. В процессе настоящего исследования при диагностировании психопатологических феноменов классического варианта синдрома психического автоматизма мы руководствовались критериями, изложенными в монографии В.Х.Кандинского "О псевдогаллюцинациях" [8], в также классификации А.В.Снежневского [7].

При диагностике психопатологических феноменов активного варианта синдрома психического автоматизма Кандинского Клерамбо бо, мы руководствовались критериями, приведенными в работах М.Г.Гулямова [3, 4, 5], а также особенностями, выявленными в процессе настоящего исследования.

Переходя к решению поставленных в исследовании задач, прежде всего, необходимо было дать определение активного варианта синдрома Кандинского-Клерамбо. Активный вариант синдрома Кандинского-Клерамбо - это сложное психопатологическое состояние, отличающееся от классического варианта синдрома двумя существенными особенностями - наличием чувства собственной внутренной деятельности и наличием чувства психического обогащения личности, вызванным извне и характеризующееся следующими психопатологическими расстройствами:

- бредом активного воздействия (появляющаяся у больных убежденность в том, что они, под воздействием извне, сами могут влиять на окружающее); -активными слуховыми псевдогаллюцинациями (возникщая под воздействием извне способность передавать свой голос в головы лбдей или вызывать у них другие голоса);

- $\quad$ активным эрительными псевдогаллюцинациями (возникшая под воздействием извне способность, настроившись на биотоки мозга других людей, вызывать у них другие в голове различные образы, видения и т.п.);

- симптомами идеаторного автоматизма (способность больных, благодаря обогащению личности, вызванному воздействием извне, читать, вкладывать и отнимать мысли окружающих, путать, перебивать их, передавать мысли на большое расстояние, измениять настроение окружающих и т.п.); 
симптомами сенестопатического автоматизма (крайне неприятные, тягостные ощущения, вызываемые больными у окружающих, благодаря обогащению личности, вызванному извне);

симптомами кинестетического автоматизма (способность больных, благодаря обогащению личности, вызванному извне, управлять действиями, поступками, движениями окружающих людей).

Проведенное комплексное клиникопсихопатологическое исследование активного варианта синдрома Кандинского - Клерамбо на модели различных форм и типов течения шизофрении позволили разработать его систематику, выявить соотношение классического и активного вариантов синдрома Кандинского - Клерамбо, обосновать его клиническое, прогностическое и судебно психиатьрическое значения.

В основу предлагаемой нами систематики активного варианта синдрома Кандинского-Клерамбо положено четыре критерия: а) выраженность психопатологическая структура синдрома в зависимости от преобладания тех или иных расстройств; в) направленность воздействия; г) особенности прогредиентности развития активного варианта синдрома КандинскогоКлерамбо.

C учетом первого критерия активный вариант синдрома Кандинского -Клерамбо проявлялся в двух разновидностях: развернутой и неразвернутой.

\section{КЛИНИКА}

ВАРИАНТА СИНДРОМА бред активного воздействия, активные слуховые и зрительные псевдогаллюцинации, симптомы ассоциативного, сенестопатического и кинестетического автоматизма.

КЛИНИКА

НЕРАЗВЕРНУТОЙ

РАЗНОВИДНОСТИ АКТИВНОГО ВАРИАНТА СИНДРОМА КАНДИНСКОГО-КЛЕРАМБО вкладывалась из бреда активного воздействия, симптомов ассоциативного и сенестопатического автоматизма, отличавшихся простотой конструкции, конркретностью и отсутствием склонности к расширению.

Второй критерий, который мы учитывали при разроботке систематики активного варианта синдрома КандинскогоКлерамбо -это его психопатологическая структура в зависимости от преобладания тех или иных проявдений синдрома. Оценка этого критерия позволила нам выделить следующие его разновидности.

\section{БРЕДОВАЯ}

РАЗНОВИДНОСТЬ АКТИВНОГО ВАРИАНТА СИНДРОМА КАНДИНСКОГО-КЛЕРАМБО. Здесь все психопатологические феномены определялись систематизированным бредом активного воздействия, проявлявшимся убежденностью больных, что окружающие люди и даже преследователи находятся в их власти, они (больные) могут управлять ими (окружающими) по своему желанию, на любых расстояниях и в любое время суток. Наши исследования показали, что эта разновидность активного варианта синдрома Кандинского-Клерамбо, нередко сопровождалась бредом активный метаморфозы, проявлявшимся в убежденности больных, что они благодаря своей способности, развивающейся под влиянием извне, могут превращать людей в лягушек, мух, животных и т.П.

\section{ПСЕВДОГАЛЛЮЦИНАТОРНАЯ}

РАЗНОВИДНОСТЬ АКТИВНОГО ВАРИАНТА СИНДРОМА КАНДИНСКОГО-КЛЕРАМБО. Эта разновидность синдрома разделена нами на два подтица.

1. Псевдогаллюцинаторно-

вербальная разновидность активного варианта синдрома Кандинского - Клерамбо. При этой разновидности психопатологические феномены синдрома определялись слуховыми псевдогаллюцинациями и тесно связанными с ними бредовыми идеями активного воздействия, которые вытекали из содержания слуховых псевдогаллюцинаций.

2. Псевдогаллюцинаторно-

эрительная или условно "грезоподобная" разновидность активного варианта синдрома Кандинского-Клерамбо развивалась в клинике онейроидно-кататонических приступов шизоаффективной шубообразной и периодической шизофрении и находилось в тесной связи с грезоподобными эрительными псевдогаллюцинациями. Так, симптомы ассоциативного автоматизма, проявлялись в высказываниях больных о том, что инопланетяне, экспериментаторы, черти, среди которых они себя видели, производя над ними эксперименты, при помощи аппаратов, космических лучей, колдовских чар, наделяли их особыми способностями, при помощи которых они читали мысли окружающих людей, 
отнимали мысли у тех же инопланетян и экспериментаторов, внушали им мысли изменияли их настроение; симтомы сенестопатического автоматизма - в том, что те же инопланетяне, черти, экспериментаторы, наделяли больных способностью вызывать неприятные ощущения в различных частях тела окружающих, при этом наблюдали, как они переживают эти ощущения.

\section{МАНИОФОРМНАЯ РАЗНОВИДНОСТЬ} АКТИВНОГО ВАРИАНТА СИНДРОМА КАНДИНСКОГО-КЛЕРАМБО, разливаясь на фоне маниакального состояния, в структуре шизоаффективных приступов шубообразной шизофрении, характеризовался тем, что все компоненты активного варианта синдрома Кандинского-Клерамбо отличались фантастичностью, однако в их основе с самого начала его развития лежал маниакальный аффект. Характерным для этой разновидности синдрома является то, что обратное развитие мании сопровождалось регрессом психопатологических феноменов активного варианта синдрома.

$$
\text { ДЕПРЕССИВНАЯ РАЗНОВИДНОСТЬ }
$$

АКТИВНОГО ВАРИАНТА СИНДРОМА

КАНДИНСКОГО-КЛЕРАМБО, развивавшаяся в клинике депрессивно - параноидных приступов шизоаффективной шубообразной и периодической шизофрении характеризовалась тем, что депрессия пронизывала красной нитью все без исключения его психопатологические феномены. Так, симптомы ассоциативного автоматизма проявлись в переживаниях больных о том, что они, в силу обогащения личности несвойственными качествами, происшедшими под влиянием извне, могут читать мысли окружающих, лишают их возможности мыслить, вкладывают им страшные мысли о гибели, их греховности, предстоящем наказании, вызывают у окружающих тоску, страх, тревогу; симптомы сенестопатического автоматизма - что при помощи своих способностей, переданных им преследователями, они вызывают страшные и мучительные ощущения у окружающих людей, заставляя их мучить и страдать, при этом в голове слышали их крики, стоны, мольбы о прекращении воздействия. Характерным для этой разновидности синдрома является то, что с обратным развитием депрессии, психопатологические феномены активного варианта синдрома Кандинского-Клерамбо также подвергались регрессу.

\section{АКТИВНЫЙ ВАРИАНТ СИНДРОМА} КАНДИНСКОГО-КЛЕРАМБО

$\mathrm{C}$ ФАНТАСТИЧЕСКИМ СОДЕРЖАНИЕМ может развиваться в рамках как бредовой, так и псевдогаллюцинаторной разновидностей синдрома. Чаще всего он развивался на отделенном этапе манифестной стадии непрерывнотекущей шизофрении и характеризовался грандиозностью и фантастическим содержанием его психопатологических феноменов. Так, симптомы ассоциатовного автоматизма здесь проявлялись в утверждениях больных о том, что в силу особых способностей, биополя, которым их одарили высшие силы, бог, они могут проникать в тайные замыслы всех людей, передавать мысли и читать их, независимо от расстояния и несмотря ни на какие преграды, могут установить телепатическую связь с космосом и т.п.; симптомы сенестопатического автоматизма проявлялись в высказываниях больных о том, что они в силу особых возможностей могут сжигать всех грешников, заставлять их мучиться как в аду, вызывая у них страшные боли и.т.п.; симптомы кинестетического автоматизма благодаря особому дару, возможностям, которые передали им преследователи, больные могут управлять действиями всего человечества, передвигать горы, управлять всеми живыми существами и т.п.

Наличие чувства сделанности, являющегося одним из существенных компонентов активного варианта синдрома Кандинского-Клерамбо, дифференцировать позволило психопатологическое состояние от бреда величия. Кроме того, наши исследования показали, что явной корреляционной связи между указанной разновидностью активного варианта синдрома Кандинского-Клерамбо и степенью выраженности негативных дефицитарных расстройств нет. Другими словами, активный вариант синдрома с фантастическим содержанием не является отражением грубых шизофренических изменений личности.

Анализ критерия направленности активного воздействия при активном варианте синдрома Кандинского-Клерамбо позволил нам выделить его аутоактивную и гетероактивную разновидности.

ПРИ АУТОАКТИВНОЙ РАЗНОВИДНОСТИ СИНДРОМА у больных появлялась убежденность в том, что они под 
воздействием извне наделены способностью оказывать влияние не только на окружающих, но и на себя: читать свои мысли, ускорять или замедлять их, заменять на другие, изменять глубинные структуры мозга, регулировать свои чувства, настроение (симптомы ассоциативного автоматизма), вызывать у себя в голове различные неприятные, но необходимые им для пользы, ощущения, направленные на самосовершенствование, путем расширения одних участков мозга, сглаживания других и т.п. (симптомы сенестопатического автоматизма). Подтверждением выделенной нами аутоактивной пазновидности активного варианта синдрома Кандинского-Клерамбо является тот факт, что способность воздействия на собственные психического акты, возикает у больных под воздействием извне и сопровождается чувством внутренней активной деятельности.

ПРИ

ГЕТЕРОАКТИВНОЙ РАЗНОВИДНОСТИ АКТИВНОГО ВАРИАНТА СИНДРОМА КАНДИНСКОГО-КЛЕРАМБО У больных появляется убежденность, что они под воздействием извне, наделены способностью воздействовать на окружающее. При этой разновидности синдрома нами наблюдался психопатологический феномен, обозначенный как ЯВЛЕНИЕ АКТИВНОГО ТРАНЗИТИВИЗМА. Это своеобразный феномен, стоящий близко к явлениям транзитивизма при классическом варианте синдрома КандинскогоКлерамбо, заключающийся в высказываниях больных о том, что способности влиять на окружающих, которые они получили, благодаря воздействию на них извне, позволили им в свою очередь одарить этими же способностями окружающих людей, которые вследствие этого сами могли читать мысли, вызывать у других людей неприятные ощущения и т.п.

Следующим критерием систематики активного варианта синдрома КандинскогоКлерамбо является его типология с учетом прогредиентности

психопатологических феноменов, его составляющих. В данном аспекте мы выделили три типа прогредиентности.

$$
\text { 1. ПРОГРЕДИЕНТНЫЙ }
$$

ТИП

РАЗВИТИЯ АКТИВНОГО ВАРИАНТА
СИНДРОМА КАНДИНСКОГО-КЛЕРАМБО. ЭТОт при прогредиентности наблюдался у части больных прогредиентной параноидной и шубообразной шизофренией, с ранним началом заболевания, у которых активный вариант синдрома Кандинского-Клерамбо формировался на начальных этапах манифестной стадии психоза. Эдесь вначале происходило усиление его психопатологических феноменов, в последующем, в динамике заболевания постепенная дезактуализация и стирание чувства сделанности, парафренизация переживаний больных, приобретающих все более нелепый и фантастический характер. Спустя 2-5лет от начала развития заболевания, на фоне выраженного шизофренического дефекта, активный вариант синдрома КандинскогоКлерамбо представлял собой распавшуюся бредовую систему, проявления которой становились оскольчатыми и прявлялись эпизодически.

\section{2. РЕГРЕДИЕНТНЫЙ ТИП РАЗВИТИЯ} АКТИВНОГО ВАРИАНТА СИНДРОМА КАНДИНСКОГО-КЛЕРАМБО. Наблюдался у части больных шизоаффективной шубообразной и у всех больных периодической шизофренией. Он характеризовался обратным развитием психопатологических феноменов активного варианта синдрома Кандинского-Клерамбо, которое в наших наблюдениях происходило по двум направлениям. При первом из них активный вариант синдрома КандинскогоКлерамбо подвергался обратному развитию очень быстро, по типу критического обрывания психоза с полным исчезновением всех его симптомов, восстановлением полной критике к перенесенному состоянию. При втором психопатологические феномены синдрома Кандинского-Клерамбо регрессировали медленно в той же последовательности, в какой они развивались. По выходе из психотического состояния, при формально правильном поведении, длительное время сохранялся резидуальный бред, на фоне различной степени выраженности изменений личности.

3. СТАЦИОНАРНЫЙ ТИП РАЗВИТИЯ АКТИВНОГО ВАРИАНТА СИНДРОМА КАНДИНСКОГО-КЛЕРАМБО. Наблюдался у больных прогредиентной параноидной шизофренией. Здесь проявления активного варианта синдрома Кандинского-Клерамбо стабилизировались, становились монотонными, стереотипными, теряли свою аффективную насыщенность, не оказывая сколь-нибудь заметного влияния на поведение больных, усиливаясь при ухудшении и вновь стабилизируясь при улучшении состояния больных.

Обсуждение результатов исследования. 
Активный вариант синдрома Кандиского-Клерамбо при шизофрении - это сложное психопатологическое состояние, отличающееся от классического варианта синдрома КандискогоКлерамбо двумя существенными особенностями: наличием чувства собственной внутренней деятельности и наличием чувства психического обогащения личности, вызванным воздействием извне. Вследствие этого больных появляется убежденность в том, что они сами могут воздействовать на окружающих. Динамика активного варианта синдрома КандискогоКлерамбо в основном предопределяется типом течения шизофрении. С позиций структурнодинамического анализа для него характерны прогредиентный, регредиентный, стационарный типы прогредиентности.

Клинические особенности активного варианта синдрома Кандиского-Клерамбо находятся в определенной зависимости от типа и формы течения шизофрении. Так, при непрерывнотекущей параноидной и прогредиентной щубообразной шизофрении психопатологические феномены активного варианта синдрома Кандиского-Клерамбо формируются на среднем и отдаленном этапах манифестной стадии или клинической картине второго и третьего приступов, отличаются завершенностью расстройств, проявляясь в виде активного варианта с фантастическим содержанием, бредовой и псевдогаллюцинаторной его разновидностей. При шизоаффективной шубообразной и периодической шизофрении психопатологические феномены активного варианта синдрома Кандиского-Клерамбо развиваются преимущественно в картине первого и реже второго приступов, отличаются незавершенностью клинических расстройств, проявляясь в виде активного варианта с фантастическим содержанием, депрессивной, грезоподобной и аутоактивной разновидностей. Между психопатологическими феноменами классического и активного вариантов синдрома Кандиского-Клерамбо прослеживается причинно обусловленная взаимосвязь и определенные закономерности перехода, которые можно условно свести в три варианта:

первые вариант взаимоперехода классического и активного вариантов синдрома Кандиского-Клерамбо характеризуется их сосуществованием на всем протяжении психоза;

- второй - активный вариант синдрома Кандиского-Клерамбо, формируясь вслед за классическим вариантом, становится доминирующим расстройством;

- третий вариант характеризуется тем, что активный вариант синдрома Кандиского-Клерамбо с момента своего появления вскоре полностью заменяет психопатологические феномены классического варианта. Первая формы соотношения наблюдается при шизоаффекктивной шубообразной и периодической шизофрении; вторая - при шубообразной и третья-при прогредиентной параноидной и части прогредиентной щубообразной шизофрении.

Прогностическое значение психопатологических феноменов активного варианта синдрома Кандиского-Клерамбо определяется его целостностью, этапом заболевания, на котором он сформировался, особенностями его взаимоотношения с классическим вариантом синдрома Кандиского-Клерамбо. Наиболее неблагоприятно в прогностическом отношении протекает прогредиентная параноидная и прогредиентная щубообразная шизофрения, где активный вариант синдрома КандискогоКлерамбо формируется на средних этапах манифестной стадии или при первых приступах болезни, отличаясь целостным содержанием и с момента своего появления полностью заменяет психопатологические феномены классического варианта синдрома Кандиского-Клерамбо. Течение болезни характеризуется быстрым нарастанием шизофренического дефекта, распадом бредовой системы, затяжным характером приступов, утратой больными социального статуса. Меньшей прогредиентностью отличается шизофрения, при которой активный вариант синдрома КандискогоКлерамбо формируется на отдаленных этапах болезни, либо в $3-4$ приступах, отличается незавершенностью клинических проявлений и сосуществует с психопатологическими феноменами классического варианта синдрома Кандиского-Клерамбо. При этом наблюдается стабилизация патологического процесса, относительная кратковременность приступов, изменения личности не достигают степени шизофренического слабоумия.

Финансовый источник: При написании статьи не использовались финансовые ресурсы.

Конфликт интересов: Нет. 


\section{СПИСОК ЛИТЕРАТУРЫ}

1. Бессонов Ю.В. Суицидальные и агрессивные действия больных параноидной шизофренией с синдромом Кандиского. -Автоферюдисс. ...канд.мед.наук. $-1980 .-19$ с.

2. Бухман Ю.М. Нозологическое видоизменение синдрома Кандинского при атеросклеротических психозах. - Дисс.канд.мед. наук. -1975.

3. Гулямов М.Г. О психопатологии и динамике острого синдрома Кандинского при некоторых экзогенных онейроидах \\ Проблемы психоневрологии (научные тезисы). - М., 1969. - С. 269-273.

4. Гулямов М.Г. Об одном из вариантов синдрома психического автоматизма Кандинского ॥ Журн. Невропатологии и психиатрии им. С.С.Корсакова. 1972. - № 12. - С.1847-1951.

5. Гулямов М.Г. О диагностическом и прогностическом значении активного варианта синдрома Кандиского при шизофрении ॥ Нозологическое видоизменение психопатологических синдромов. - Душанбе, 1974. - С.51-56.

6. Дикая В.И. Клинико - психопатологические разновидности острого синдрома Кандинского Клерамбо при шизофрении \ Журн. Невропатологии и психиатрии им. С.С.Корсакова. - 1985. - № 8. С. $1200-1205$.

7. Снежневский А.В. Симптоматология психических заболеваний // Учебник психиатрии. М., 1958. - С.78.

8. Снежневский А.В. В.Х.Кандинский // В.Х.Кандинский «О псведо-галлюцинациях». - М., 1952. - С. 147-167.

9. Шарапова Н.М. Клиника и формирование синдрома Кандинского-Клерамбо при остром алкогольном галлюцинозе. -Автореф.дисс. ...канд.мед.наук. - 1986. -18c. 